\title{
Virus-Host Interplay Between Poly (ADP-Ribose) Polymerase 1 and Oncogenic Gammaherpesviruses
}

\author{
Woo-Chang Chung and Moon Jung Song* \\ Virus-Host Interactions Laboratory, Department of Biotechnology, College of Life Sciences and Biotechnology, Korea \\ University, Seoul, South Korea
}

OPEN ACCESS

Edited by:

Rohit K. Jangra,

LSU Health Sciences

Center-Shreveport, United States

Reviewed by:

Hongyan Guo,

Louisiana State University Health Science Center Shreveport,

United States

Qiliang Cai,

Fudan University, China

*Correspondence:

Moon Jung Song

moonsong@korea.ac.kr

Specialty section:

This article was submitted to

Virology,

a section of the journal

Frontiers in Microbiology

Received: 09 November 2021

Accepted: 23 December 2021

Published: 14 January 2022

Citation:

Chung W-C and Song MJ (2022)

Virus-Host Interplay Between Poly

(ADP-Ribose) Polymerase 1

and Oncogenic

Gammaherpesviruses.

Front. Microbiol. 12:811671. doi: 10.3389/fmicb.2021.811671
The gammaherpesviruses, include the Epstein-Barr virus, Kaposi's sarcoma-associated herpesvirus, and murine gammaherpesvirus 68 . They establish latent infection in the B lymphocytes and are associated with various lymphoproliferative diseases and tumors. The poly (ADP-ribose) polymerase-1 (PARP1), also called ADP-ribosyltransferase diphtheria-toxin-like 1 (ARTD1) is a nuclear enzyme that catalyzes the transfer of the ADP-ribose moiety to its target proteins and participates in important cellular activities, such as the DNA-damage response, cell death, transcription, chromatin remodeling, and inflammation. In gammaherpesvirus infection, PARP1 acts as a key regulator of the virus life cycle: Iytic replication and latency. These viruses also develop various strategies to regulate PARP1, facilitating their replication. This review summarizes the roles of PARP1 in the viral life cycle as well as the viral modulation of host PARP1 activity and discusses the implications. Understanding the interactions between the PARP1 and oncogenic gammaherpesviruses may lead to the identification of effective therapeutic targets for the associated diseases.

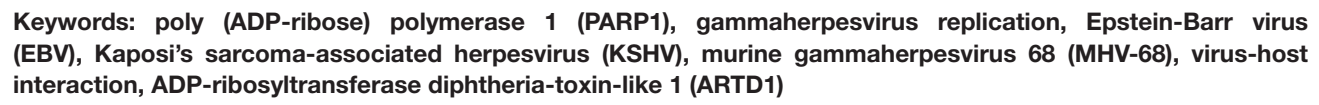
(EBV), Kaposi's sarcoma-associated herpesvirus (KSHV), murine gammaherpesvirus 68 (MHV-68), virus-host interaction, ADP-ribosyltransferase diphtheria-toxin-like 1 (ARTD1)

\section{INTRODUCTION}

Post-translational modifications are important molecular mechanisms through which a cell regulates the diverse functions of proteins in various biological processes. Among the various cellular post-translational modifications, ADP-ribosylation constitutes a major modification. It involves the covalent attachment of the ADP-ribose unit from nicotinamide adenine dinucleotide $(\mathrm{NAD}+)$ onto a target protein. Depending on the acceptor proteins or catalyzing enzymes, ADPribosylation may involve the addition of a single unit or a polymer of ADP ribose units. The main proteins catalyzing ADP-ribosylation are PAR polymerases (PARPs) (Gupte et al., 2017). To date, 18 PARPs have been identified in the human genome, based on the conserved PARP motif (Amé et al., 2004; Jubin et al., 2016). Among these, PARP1 is the most abundant protein and has been widely studied as a major PARylating enzyme (Bai, 2015). PARP1 is involved in several cellular events, such as DNA repair, transcription, DNA replication, chromatin remodeling, energy metabolism, and cell death via PARylating target proteins (Kim et al., 2005; Ko and Ren, 2011; Gibson and Kraus, 2012; Luo and Kraus, 2012). Moreover, PARP1 is critical in viral infections, including the retroviruses, herpesviruses, influenza virus, hepatitis B virus, and chikungunya virus (Kameoka et al., 1999, 2005; 
Dandri et al., 2002; Zhang et al., 2002; Ko and Ren, 2011; Grady et al., 2012; Bueno et al., 2013; Rom et al., 2015; Na et al., 2016; Xia et al., 2020).

The human gammaherpesviruses such as the EpsteinBarr virus (EBV) and Kaposi's sarcoma-associated herpesvirus (KSHV), are important pathogens associated with various tumors and proliferative diseases (Arvin et al., 2007; Jha et al., 2016). The murine gammaherpesvirus 68 (MHV-68) is genetically and biologically related to the human gammaherpesviruses. MHV-68 is extensively studied for elucidating the virus-host interactions and pathogenesis of gammaherpesviruses (Speck and Virgin, 1999; Virgin and Speck, 1999; Nash et al., 2001). These oncogenic herpesviruses display host cell tropisms, infecting epithelial, endothelial, fibroblastic, and lymphoblastic cells for their replication and establishing latency in lymphoid tissues, mainly $\mathrm{T}$ or B cells, through which they establish a persistent life-long infection in the hosts (Roizman et al., 1981). Interestingly, various host proteins have been identified to regulate gammaherpesvirus infections (Ye et al., 2011; Lee et al., 2012; Murata, 2014; Niller et al., 2014). Among these, PARP1 plays a key role in regulating the life cycle of the gammaherpesvirus. In this review, we have summarized the roles of PARP1 in the latent and lytic infection phases of the gammaherpesviruses, such as KSHV and EBV, and discussed how these oncogenic herpesviruses modulate PARP1 to promote their replication in the host. Furthermore, this review discusses the implications and the future perspectives of the activities of PARP1 on modulating these viruses.

\section{PARP1: Biological Functions}

PARPs or ADP-ribosyltransferase diphtheria-toxin-like (ARTDs) are enzymes that catalyze the transfer of the ADP-ribose unit from $\mathrm{NAD}^{+}$to specific residues in the target proteins, resulting in the addition of ADP-ribose polymers, a process termed as PARylation (Kawaichi et al., 1980; Ogata et al., 1980a,b). Therefore, the availability of the $\mathrm{NAD}^{+}$pool in the cells is a key factor for the activity of PARPs. PARP1 is the founding member among the 18 human PARPs. This highly conserved eukaryotic nuclear protein is known to play a role in DNA damage response, chromatin modification, transcriptional regulation, inflammation, and cell death (Gibson and Kraus, 2012). PARP1 mediates approximately $90 \%$ of the cellular PARylation in response to DNA damage (Bai, 2015). PARP1 is responsible for the majority of cellular PARP activity, followed by PARP2, while the activities of other PARPs seem to be negligible in comparison (Bai, 2015). The PARylated proteins can be reversely hydrolyzed by PAR glycohydrolase (PARG), ADPribosylhydrolase 3 (ARH3), or O-acyl-ADP-ribose deacylase 1 (OARD1) to remove the PAR chain from the target protein and catabolize ADP-ribose (Oka et al., 1984, 2006; Davidovic et al., 2001; Rosenthal et al., 2013; Sharifi et al., 2013). A schematic diagram for addition or removal of PAR to an acceptor protein is shown in Figure 1A.

PARP1 contains three domains, an N-terminal DNA-binding domain (DBD), a central auto-modification domain (AD), and a C-terminal catalytic domain (CAT) (Alvarez-Gonzalez et al., 1999; Affar et al., 2001; Kim et al., 2005; Figure 1B). The DBD contains three zinc-finger motifs (ZnFI, ZnFII, and ZnFIII) and a nuclear localization sequence and are responsible for recognizing the DNA breaks such as a single-strand break (SSB) or doublestrand break (DSB) (Caldecott et al., 1996; Langelier et al., 2008, 2011, 2012). The AD includes the BRCA1 C-terminus (BRCT) motif, flanked by lysine and glutamate residues as autoPARylation sites (Altmeyer et al., 2009; Tao et al., 2009). The BRCT motif mediates interactions with other proteins involved in various cellular pathways (Masson et al., 1998; Beernink et al., 2005; Cuneo et al., 2011). The CAT domain contains a helical WGR domain and an ADP-ribosyltransferase (ART) domain that is conserved in the PARP family proteins (Hottiger et al., 2010). It is responsible for catalyzing the addition of ADPribose units onto target proteins and their subsequent elongation and branching (Mendoza-Alvarez and Alvarez-Gonzalez, 1993). PARP1 has been reported to interact with and/or PARylate various cellular factors including PARP1 itself to modulate their functions (Gibson and Kraus, 2012; Ciccarone et al., 2017; Kamaletdinova et al., 2019). Although domain-mapping studies for protein-protein interactions using domain mutants of PARP1 have not been done for all the interacting proteins, representative binding partners for its individual domains are listed and marked with the associated cellular activities in Figure 1B (Kraus and Lis, 2003; Glover et al., 2004; Strosznajder et al., 2005; Li et al., 2006; Kanno et al., 2007; Hassa and Hottiger, 2008; Kotoglou et al., 2009; Krishnakumar and Kraus, 2010; Chang et al., 2011; Rodríguez et al., 2011; Gibson and Kraus, 2012; Ko and Ren, 2012; Mangerich and Bürkle, 2012; Xie et al., 2015; Bonfiglio et al., 2017; Ray Chaudhuri and Nussenzweig, 2017; Alemasova and Lavrik, 2019; Kamaletdinova et al., 2019; Ke et al., 2019; Fehr et al., 2020; Demény and Virág, 2021).

\section{PARP1 and Viral Infections}

PARP1 plays important roles in infections of viruses with DNA genome. For example, PARP1 binds to the hepatitis B virus (HBV) core promoter and enhances viral gene transcription and HBV replication (Ko and Ren, 2011). A study on PARP1 inhibitors suggested that PARP1 activity may limit the integration of the HBV DNA (Dandri et al., 2002). As an essential factor for $\mathrm{HBV}$ replication, $\mathrm{HBx}$ interacts with PARP1 and inhibits the recruitment of the DNA repair machinery to the damaged DNA sites, thereby promoting hepatocarcinogenesis ( $\mathrm{Na}$ et al., 2016). In vaccina virus infection, PARP1 plays a role in NK cell migration to the site of infection and promotes CCL2 production (Shou et al., 2019). Herpes simplex virus 1 degrades the poly (ADP-ribose) glycohydrolase (PARG) using the viral E3ligase, ICP0 and activates PARP1 to facilitate virus replication (Grady et al., 2012).

PARP1 activity also regulates the replication of many RNA viruses. In human immunodeficiency virus 1 (HIV-1) infection, PARP1 activation increases the integration of the HIV-1 genome into the host chromosome (Ha et al., 2001; Kameoka et al., 2005). PARP-1 activity also increased long terminal repeat (LTR)-mediated viral gene transcription (Kameoka et al., 1999; Rom et al., 2015). In contrast, there are reports showing a negative role of PARP-1 in viral gene transcription (Parent et al., 2005; Bueno et al., 2013). For human T-lymphotropic virus 1 (HTLV-1), PARP1 activates transcription of Tax binding elements 


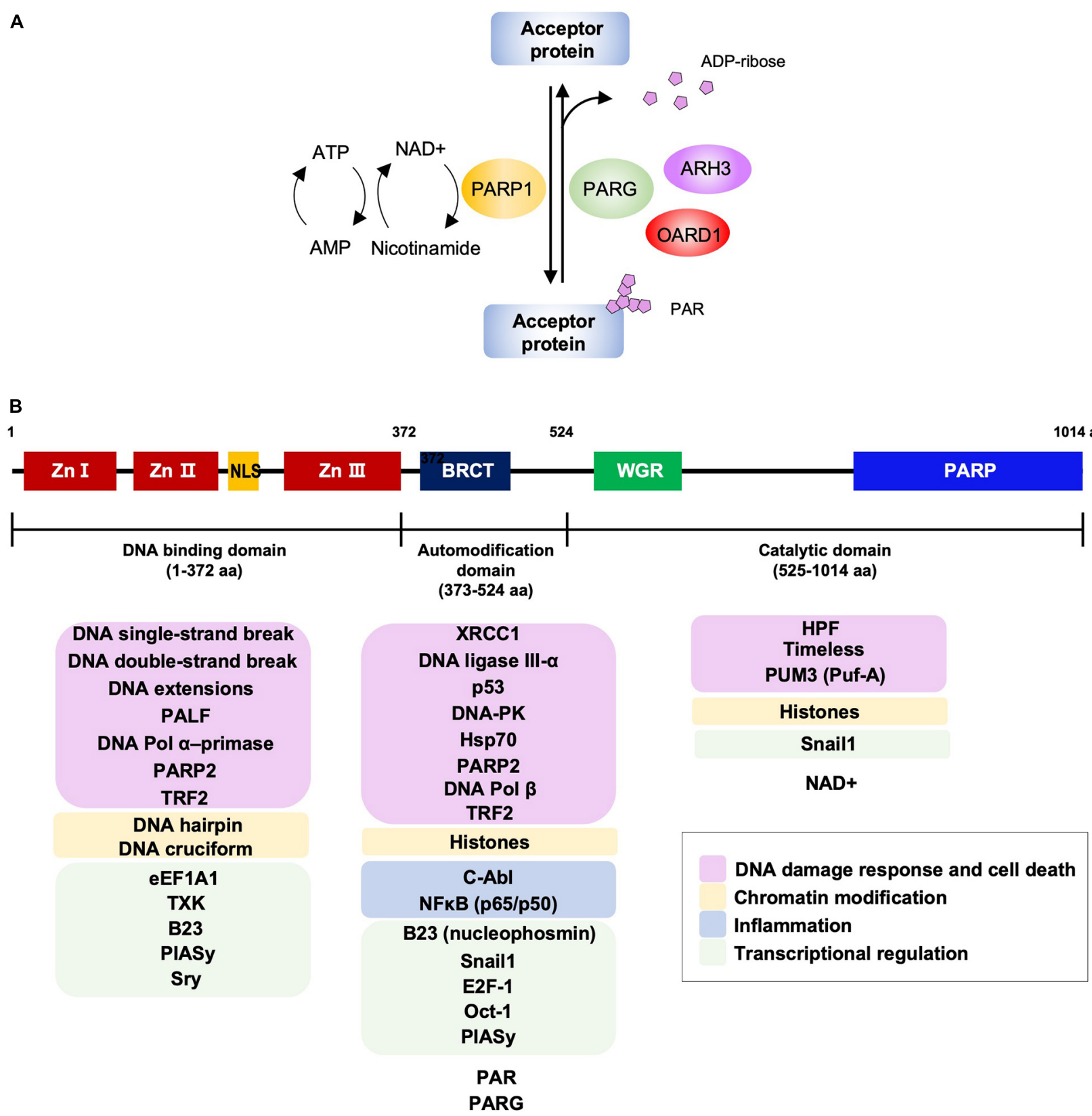

FIGURE 1 | PARP1-mediated PARylation and PARP1 structural domains with interacting partners. (A) The PARylation reaction by PARP1. The activated PARP1 hydrolyses $\mathrm{NAD}^{+}$and catalyzes the transfer of ADP-ribose moiety onto target residues of the acceptor protein (PARylation). The PARylated proteins are involved in various biological processes, including DNA repair, cell death, chromatin remodeling, inflammation, and transcription. PAR chains from the PARylated acceptor proteins are rapidly catabolized by PAR glycohydrolase (PARG), ADP-ribosylhydrolase 3 (ARH3), and O-acyl-ADP-ribose deacylase 1 (OARD1). NAD+, nicotinamide adenine dinucleotide. (B) Schematic representation of PARP1 domains and interaction partners. PARP1 contains three domains; the N-terminal DNA binding domain that has three zinc finger motifs with DNA binding activity and an NLS that is responsible for the localization of PARP1 into the nucleus; the auto modification domain that has a BRCT domain and is responsible for its auto-PARylation; the catalytic domain that contains a homologous PARP family motif and catalyzes PARylation of the target proteins. According to the studies using PARP1 domain mutants, PARP1 interacting partners for each domain are listed and marked for the associated cellular activities. Zn I, Zn II, and Zn III: zinc finger motifs; NLS, nuclear localization signal; BRCT, BRCA1 C-terminus motif; WGR, tryptophan-glycine-arginine-rich domain; PARP, PARP activity domain.

(Zhang et al., 2002). In Influenza A virus, hemagglutinin (HA) interacts with PARP1 and degrades type I interferon receptor (IFNAR), thereby enhancing virus replication (Xia et al., 2020). PARP1 interacts with the nucleocapsid $(\mathrm{N})$ protein of porcine reproductive and respiratory syndrome virus (PRRSV) and its activity promotes the virus replication (Liu et al., 2015). Sindbis virus (SINV), belonging to the Alphavirus, activates PARP1 during infection (Ubol et al., 1996; Nargi-Aizenman et al., 2002). 
PARP1 is found in the SINV replication complex and interacts with nsP3, suggesting its positive role in the replication of SINV (Park and Griffin, 2009). Overall effects of PARP1 on regulation of viral replication can be either proviral or antiviral, while the effects appear to be both in HIV1 infection.

\section{PARP1 IN EBV INFECTION}

EBV, a member of Lymphocryptovirus genus, is the first discovered human oncovirus that is associated with Burkitt's lymphoma, infectious mononucleosis, Hodgkin's disease, nasopharyngeal carcinoma, gastric carcinoma, and various other lymphomas (Rickinson, 2014). It has a worldwide prevalence with over $95 \%$ of the adults being seropositive for EBV (Luzuriaga and Sullivan, 2010). As it spreads primarily through saliva, most of the individuals are infected during infancy and early childhood asymptomatically or with non-specific symptoms.

\section{Life Cycle of EBV}

EBV is known to spread mainly through body fluids, such as saliva, blood, and semen, while organ transplantation is also a potential transmission route (Chang et al., 2009). After primary infection, the virus remains latent in the individuals for the rest of their lives. EBV establishes latency mainly in the B lymphocytes and is reactivated intermittently by the induction of lytic replication (Dugan et al., 2019). A subset of viral genes is expressed to maintain latency that causes proliferation of the infected B lymphocytes. EBV-infected cells exhibit three latency programs, latency I, II, or III. Latency I restricts the expression to that of the most latent genes, while latency III involves the expression of a full repertoire of the known latent genes. During latency III, the EBV nuclear antigens (EBNAs 1, 2, 3A, 3B, 3C, and LP), latent membrane proteins (LMPs 1, 2A, and 2B), and viral non-coding RNAs (EBERs, miRNAs, and BARTs) are expressed, establishing the lymphoblastoid cell lines (Rickinson, 2002). The selective pressure from the EBV-specific cytotoxic lymphocytes leads to the transition from latency III to more restricted forms of latency. Latency II is characterized by the lack of EBNA2 and EBNA3 expression but exhibits the expression of other latent genes (Price and Luftig, 2015). EBNA1 is the only viral gene expressed in latency I. In latency 0 , the viral genome persists in the host cells without viral gene expression, which is associated with infection in the non-dividing memory B-cells (Dugan et al., 2019). When EBV reactivation is induced, the immediate-early (IE) genes, BZLF1 and BRLF1 are transcribed to produce Zta (also called ZEBRA or EB1) and Rta (also called R), respectively. After the synthesis of these transcription factors, the downstream lytic genes, including their promoters, are activated, resulting in a full cascade of lytic gene expression. The early (E) genes encode proteins required for DNA replication and metabolism, such as the viral DNA polymerase, viral DNA primase, processivity factor, and thymidine kinase. Following viral DNA replication, the late (L) genes are transcribed for the synthesis of structural proteins to assemble the virion particles (Young et al., 2007).

\section{Roles of PARP1 in EBV Infection}

PARP1 is involved in the regulation of EBV latent infection (Figure 2A). During latency, the replication of viral DNA depends on the interaction between EBNA1 and origin of plasmid replication (OriP) in the virus (Kennedy and Sugden, 2003; Lindner and Sugden, 2007). PARP1 was identified as one of the cellular factors that bind to the dyad symmetry (DS) elements of the OriP, the site for EBNA1 binding (Deng et al., 2002, 2005; Tempera et al., 2010). Treatment of D98 cells with the PARP inhibitors, such as niacinamide (NA) and 3 -aminobenzamide (3-ABA), resulted in a significant increase in the OriP plasmid maintenance after 3 weeks of treatment (Deng et al., 2002, 2005; Tempera et al., 2010). In contrast, a ribonucleotide reductase inhibitor, hydroxyurea $(\mathrm{HU})$, that increases PARP1 activity, caused a substantial loss of the OriP plasmids in these cells, which was consistent with a previous report that $\mathrm{HU}$ accelerated the loss of EBV genomes from Akata cells (Srinivas et al., 1998; Deng et al., 2002, 2005; Tempera et al., 2010). Mechanistically, PARP1 was shown to induce PARylation of EBNA1, which reduced the binding affinity of EBNA1 to the DS of OriP (Tempera et al., 2010). Studies on PARP1 knockdown and treatment with PARP1 inhibitors further suggest that PARP1 suppresses EBNA1 binding and the recruitment of origin recognition complex 2 (ORC2) onto OriP, leading to a reduction in the replication of viral DNA during latency (Tempera et al., 2010). In addition, PARP1 is colocalized with the CCCTC-binding factor (CTCF), a host insulator protein that binds to specific sites throughout the EBV genome including the latency promoter Cp (Lupey-Green et al., 2018). PARP1 PARylates CTCF and studies involving PARP1 inhibitors showed that PARP1 stabilizes CTCF binding and maintains the open chromatin structure of the EBV genome at the active $C p$ promoter during type III latency (Lupey-Green et al., 2018). Taken together, these results suggest that PARP1 and PARylation of EBNA1 and CTCF are important mechanisms regulating the viral episome during EBV latency.

A recent study indicated the involvement of PARP1 in the lytic cycle of the EBV replication. PARP1 binds to the BZLF1 promoter in the type I and type III latently infected B-cells and prevents binding of Zta to its promoter for autoregulation, thereby limiting the EBV reactivation (Lupey-Green et al., 2017). In another study, treatment with the PARP1 inhibitor, 3-ABA, during EBV reactivation increased early antigen expression (Mattiussi et al., 2007). However, PARP1 inhibition increased LMP1 and EBNA2 expression, but decreased the expression of BFRF1, a nuclear egress protein, reducing the overall virion production in the culture media (Mattiussi et al., 2007). These results suggest that PARP1 enzymatic activity may play a role in the progression of the EBV lytic cycle.

\section{Viral Modulation of PARP1 in EBV Infection}

In EBV-associated tumorigenicity, LMP1 employs PARP1 for epigenetic control. LMP1 expressed in type II and III latency programs is the major transforming protein that is critical for EBV-induced B-cell transformation and modulate several 
processes, such as differentiation, cell migration and survival, and tumorigenicity (Li and Chang, 2003; Shair et al., 2012; Liu et al., 2018). Martin et al. (2016) reported that LMP1 hijacks PARP1 to enhance the cellular PARylation level and thus enhances cellular transformation. They showed that PARP1 suppressed the expression of enhancer of zeste 2 polycomb repressive complex 2 subunits (EZH2), a histone methyltransferase, and a catalytic component of the initiation complex, polycomb repressive complex 2 (PRC2); this, in turn, reduced the level of the repressive histone marker, trimethylation of lysine 27 on histone $\mathrm{H} 3$ (H3K27me3), and induced the expression of LMP1-related protooncogenes $c$ Fos and EGR1 (Martin et al., 2016). Hulse et al. (2018) showed that LMP1 activated PARP1 to increase the hypoxiainducible factor 1-alpha (HIF-1 $\alpha$ )-dependent gene expression. In latently infected cells, LMP1-activated PARP1 acts as a coactivator of HIF-1 $\alpha$, forming the PARP1-PARylated-HIF-1 $\alpha$ complex, as depicted in Figure 2A. This complex bound to the promoters of genes downstream of $H I F-1 \alpha$ and increased their expression, resulting in altered cell metabolism and a switch from mitochondrial respiration to a glycolytic "Warburg" metabolism (Hulse et al., 2018).

EBV suppresses the inhibitory effect of PARP1 to achieve successful lytic replication (Figure $3 \mathbf{A}$ ). Upon reactivation, PARP1 was downregulated and BZLF1-encoded Zta overexpression reduced PARP1 levels to some extent, which contributes to the easy accessibility of BZLF1 promoter. This makes Zta bind to BZLF1 promoter and facilitates lytic replication (Lupey-Green et al., 2017). In KSHV and MHV-68, viral processivity factors were shown to downregulate PARP1 in a proteosome-dependent manner. In EBV infection, BMRF1 geneencoded EA-D primarily acts as a DNA polymerase processivity

\section{A}

\section{EBV}

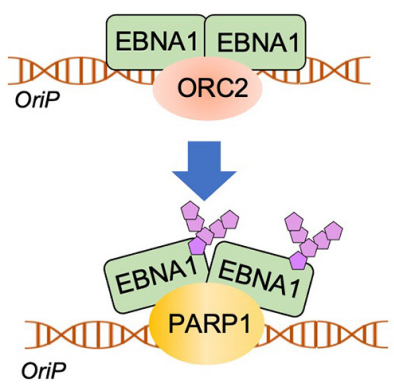

\section{- PARP1 reduced EBNA1 binding to DS leading to decreased viral DNA replication}

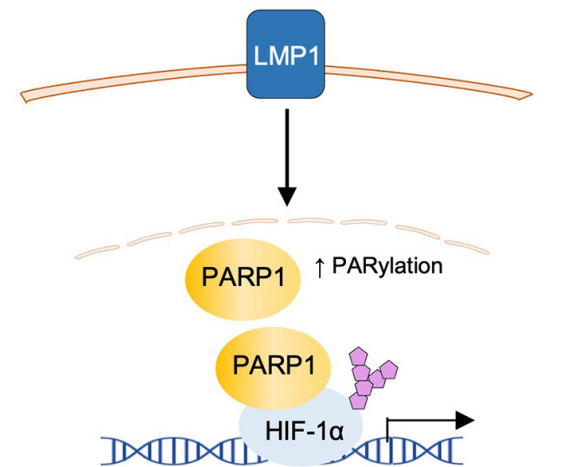

- LMP1-induced PARP1 activity reduced repressive histone modification, leading to increased proto-oncogene expression

- LMP1-induced PARP1 activation increased HIF-1a downstream gene expression for glycolytic proliferative metabolism
B

KSHV

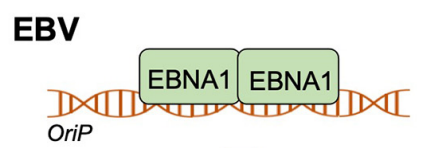

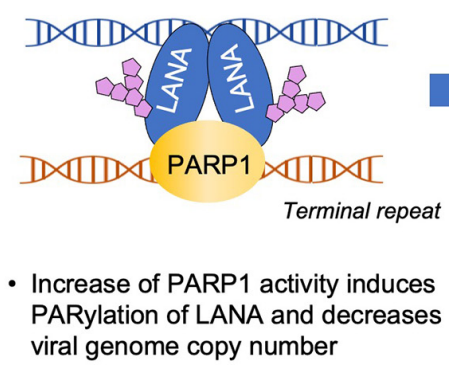

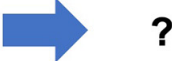

$?$

- The function of PARylated LANA needs to be elucidated

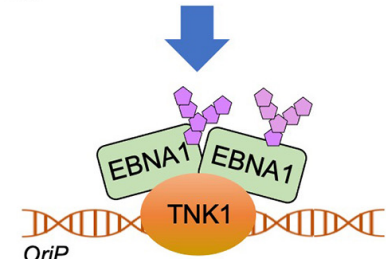

- TNK1 (aka PARP5) reduces EBNA1 binding to FR region of OriP, leading to decrease of viral DNA replication

FIGURE 2 | Molecular Interactions of PARP1 or TNK1 with gammaherpesviruses during latency. PARP1 modulates latent infection of gammaherpesviruses, EBV (A) or KSHV (B). In turn, LMP1 induces PARP1 activity, contributing to the tumorigenesis of EBV. (C) TNK1 (aka PARP5) downregulates the EBNA1-dependent OriP replication. The detailed mechanisms are explained in the text and summarized in Table $\mathbf{1 .}$ 
factor as a component of the viral DNA replication complex to facilitate DNA synthesis (Kiehl and Dorsky, 1991; Tsurumi, 1993; Neuhierl and Delecluse, 2006). It will be intriguing to find out whether EBV EA-D may downregulate PARP1 in a similar way, suggesting a conserved viral mechanism for PARP1 downregulation among gammaherpesviruses.

\section{PARP1 IN KSHV AND MHV-68 INFECTIONS}

After its identification as an infectious agent of Kaposi's sarcoma (KS), KSHV was confirmed as the eighth member of the human herpesviruses (HHV-8) and classified as a member of the

A

EBV

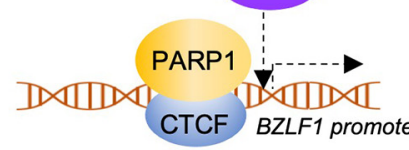

- PARP1 binds to the BZLF1 promoter and prevents Zta from binding to it

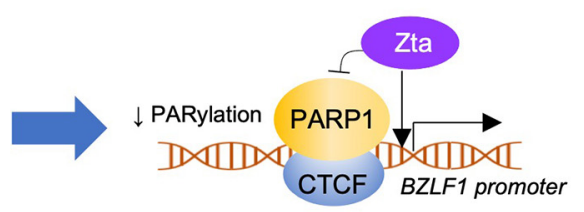

[Productive lytic replication]

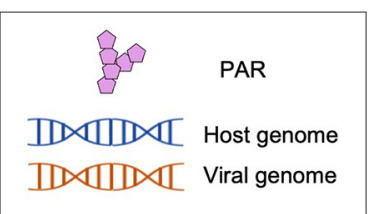

- EBV reactivation attenuates PARP1 restriction

- Zta downregulates PARP1 activity

B

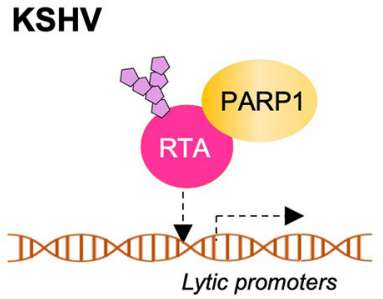

- PARylation of KSHV RTA represses RTA-mediated transactivation
C

\section{MHV-68}

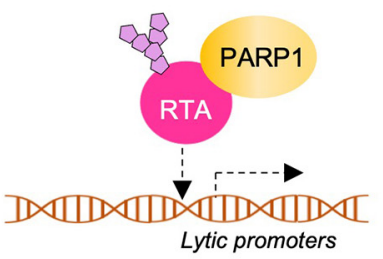

\footnotetext{
- PARylation of MHV-68 RTA represses RTA-mediated transactivation
}

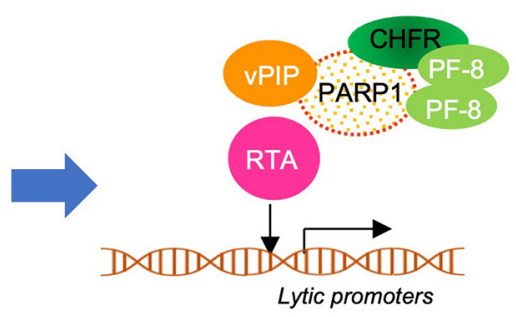

[Productive lytic replication]

- KSHV vPIP encoded by ORF49 binds to and sequesters PARP1 from RTA

- KSHV PF-8 binds to and degrades PARP1 via recruitment of CHFR, a cellular E3 ligase

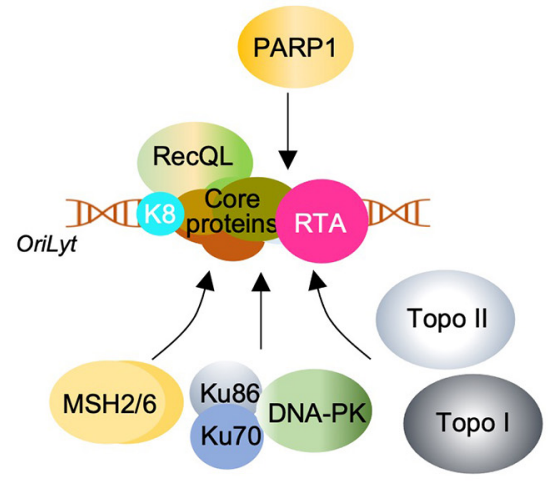
- PARP1 binds to Orilyt of KSHV
- Enhanced PARP1 activity increased
KSHV DNA replication but not virion
- PARP1 binds to Orilyt of KSHV
- Enhanced PARP1 activity increased
KSHV DNA replication but not virion
- PARP1 binds to Orilyt of KSHV
- Enhanced PARP1 activity increased
KSHV DNA replication but not virion production

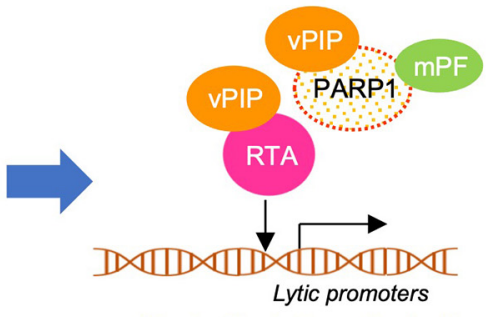

[Productive lytic replication]

FIGURE 3 | Molecular Interactions between PARP1 and gammaherpesviruses during lytic replication. PARP1 regulates Iytic replication of EBV (A), KSHV (B), or MHV-68 (C). The viruses also, in turn, modulate PARP1 via sequestering or degrading PARP1 to promote virus replication. The detailed mechanisms are explained in the text and summarized in Table 1. 
Rhadinovirus genus of the gammaherpesvirus subfamily, based on its genome sequence and homology analysis (Chang et al., 1994; McGeoch and Davison, 1999). In addition to KS, KSHV is associated with primary effusion lymphoma (PEL), multicentric Castleman's disease (MCD), body-cavity-based lymphoma, and other lymphoproliferative diseases (Di Alberti et al., 1997; Rettig et al., 1997; Ganem, 2007). Epidemiology showed that $50 \%$ of the adults in sub-Saharan Africa and less than 5\% of the adults in northern Europe, North America, and Asia are seropositive for KSHV (Simpson et al., 1996; Calabro et al., 1997; Whitby and Boshoff, 1998). Similar to EBV, saliva is the main transmission route for KSHV, but sexual contact, blood transfusion, and organ transplantation are also considered important routes (Mayama et al., 1998; Corey et al., 2002; Henke-Gendo and Schulz, 2004; Martro et al., 2004). MHV-68 (also known as $\gamma$ HV-68), another member of the Rhadinovirus genus, is homologous to EBV and KSHV in terms of genome organization and pathogenesis and is therefore considered an excellent small animal model to study virus-host interactions and viral pathogenesis of human gammaherpesviruses (Simas and Efstathiou, 1998). MHV-68 also provides an amenable genetic system to investigate viral gene functions in vitro and in vivo.

\section{Life Cycle of KSHV and MHV-68}

After primary infection of the permissive cells, KSHV enters the latent phase and only expresses the latency-associated genes without productive lytic replication. Unlike EBV, KSHV does not induce immortalization of the B-cells nor direct transformation of any infected cells (Myoung and Ganem, 2011). Moreover, there are no diverse latency programs in KSHV, albeit a subset of latent genes may be differentially expressed depending on the cell type. During latency, only a few genes are expressed; these include the open reading frame (ORF)73 encoding the latencyassociated nuclear antigen (LANA or LNA), ORF72 encoding a viral cyclin D homolog (vCyclin), and ORF71 encoding a viral Fas-associated protein with death domain-like interleukin$1 \beta$-converting enzyme/caspase-8-inhibitory protein (vFLIP), as well as those encoding K12, viral interferon regulatory factors (vIRFs), and viral miRNAs (Cai et al., 2010). LANA is a major latent protein expressed in KSHV-positive malignancies serving as a hallmark for KSHV latency (Rainbow et al., 1997; Gao et al., 1999). It is necessary for DNA replication, maintenance, and segregation of the KSHV episomes during host cell mitosis (Hu et al., 2002; Purushothaman et al., 2016). LANA also acts as a multifunctional nuclear protein, interacting with various cellular proteins involved in tumorigenesis, cellular transcription, and chromatin remodeling (Purushothaman et al., 2016; Wei et al., 2016). When reactivation is induced in the KSHV latentlyinfected cells, transcription cascade of viral lytic genes activates transcription of the $I E$ genes, followed by $E$ and $L$ genes, leading to the production of infectious virions (Sun et al., 1998; Gradoville et al., 2000; Lukac and Yuan, 2007; Schulz and Chang, 2007; Cai et al., 2010). Notably, the replication and transcription activator (RTA), mainly encoded by ORF50, acts as a key switch molecule to induce the expression of lytic genes (Lukac et al., 1998, 1999; Sun et al., 1998; Gradoville et al., 2000; Xu et al., 2005). Several cellular factors including PARP1 regulate the RTA activity either negatively or positively, thereby regulating the virus life cycle (Li et al., 2014; Aneja and Yuan, 2017; Yan et al., 2019).

The life cycle of MHV-68 is similar to that of KSHV in many aspects with some discrepancies. De novo infection of MHV-68 results in robust lytic replication in the fibroblasts and epithelial cells (Wu et al., 2000; Rochford et al., 2001). MHV-68 RTA, mainly encoded by ORF50, is also essential for activating the cascade of downstream lytic gene expression and inducing lytic replication (Liu et al., 2000; Wu et al., 2000). Moreover, MHV-68 LANA, a homolog of the KSHV LANA, plays an important role in establishing and maintaining viral latency (Fowler et al., 2003; Moorman et al., 2003; Habison et al., 2012).

\section{Roles of PARP1 in KSHV and MHV-68 Infections}

PARP1 affects the latent infection of KSHV (Figure 2B). Together with other known replication factors, such as ORC2, CDC6, and $\mathrm{Mcm} 7$, PARP1 was identified as a cellular factor that binds to the terminal repeat (TR) of the KSHV genome (Ohsaki et al., 2004). Although PARP1 was colocalized with LANA and induced its PARylation, PARP1 binding to a specific region within the TR was independent of LANA, which leaves the function of PARylated LANA to be elucidated. Nevertheless, NA (a chemical inhibitor of PARP1) treatment increased the viral genome copy number in BC-3 cells, whereas HU (a PARP1 activator) treatment decreased it, suggesting that PARP1 may play a role in maintaining KSHV latency. PARP1 and LANA interaction was also confirmed using the affinity purification method using the N-terminus of LANA (Barbera et al., 2006a). Although Ku70, Ku80, and PARP1 were found to be interacting partners in this study, neither of these factors have been shown to mediate LANA chromosome association (Barbera et al., 2006a). However, the binding of PARP1 to the TR might play a role in genome circularization and latent genome maintenance associated with LANA. Further studies are needed to identify this role (Barbera et al., 2006b).

PARP1 is also an important cellular factor that negatively regulates lytic replication of KSHV (Figure 3B). PARP1 suppresses the KSHV RTA activity by directly binding to and PARylating RTA (Gwack et al., 2003). RTA PARylation decreases the RTA-mediated transcriptional activity by inhibiting the recruitment of RTA to the promoters of lytic genes. Gwack et al. (2003) showed that PARP1 and Ste20-like kinase hKFC interacted with the serine/threonine-rich region of RTA. These two factors synergistically enhanced their interactions with RTA as well as post-translational modifications of RTA, such as PARylation and phosphorylation, thereby acting as strong repressors of the RTA activity on lytic gene expression (Gwack et al., 2003). Using mutant RTA constructs, Ko et al. (2012) showed that the Thr-366 and Thr-367 residues of RTA formed the primary motif for O-GlcNAcylation in vivo, which plays a role in the recruitment of PARP1 to RTA. In contrast, PARP1 reportedly plays a positive role in regulating DNA replication during the lytic phase. Using DNA affinity purification, Wang et al. (2008) identified topoisomerases (Topo) I and II, MSH2/6, RecQL, DNA-PK, Ku86/70, scaffold attachment factor A (SAFA), and PARP1 as KSHV oriLyt-bound proteins. Inhibition of 
PARP1 using chemical inhibitors (3-ABA and NA) resulted in decreased oriLyt-dependent DNA replication, whereas HU increased PARP1 activity and DNA replication, suggesting a positive role for PARP1 during the lytic replication of KSHV (Wang et al., 2008). Although the roles of PARP1 in KSHV lytic replication were seemingly inconsistent, Wang et al. (2008) also showed that the overall effect of PARP1 lies in reducing KSHV virion production; the result of lytic replication, suggesting that viral DNA replication may not be the rate-limiting step in virion production and that PARP1-mediated inhibition of RTA activity may be the key step that regulates the KSHV life cycle. Interestingly, the inhibitory effect of PARP1 on virus lytic replication is also conserved in MHV-68 (Gwack et al., 2003). PARP1 reduces the transcriptional activity of MHV-68 RTA and virus lytic replication during de novo infection (Figure 3C).

\section{Viral Modulation of PARP1 in KSHV and MHV-68 Infections}

To counteract the inhibitory effect of PARP1 on virus lytic replication, KSHV and/or MHV-68 have been shown to employ two viral proteins during different stages of the life cycle (Figures 3B,C). The MHV-68 ORF49-encoded protein, a tegument protein, interacts with and sequesters PARP1 from RTA binding (Noh et al., 2012; Chung et al., 2018). The purified recombinant ORF49 protein from MHV-68 and KSHV interacts directly with PARP1 without any additional cellular factors and is therefore termed viral PARP1 interacting protein (vPIP) (Noh et al., 2012; Chung et al., 2018). vPIP enhances RTAmediated transactivation by reducing the level of PARylated RTA. Owing to its association with the virion, vPIP is likely to modulate PARP1 function during the early phase of de novo infection. Consistent with this hypothesis, the viral growth of a recombinant MHV-68 with transposon or triple stop codons inserted at the ORF49 locus is significantly attenuated in vitro and in vivo. Furthermore, vPIP residues that are critical for PARP1 interaction were identified based on the vPIP crystal structure (Chung et al., 2018). A recombinant MHV-68 harboring mutations at the three critical residues of vPIP exhibited defective PARP1 interaction and was highly attenuated in viral growth both in vitro and in vivo, suggesting the significant role of vPIP and PARP1 interaction in derepressing RTA for viral replication.

Other studies have reported that KSHV and MHV-68 downregulate PARP1 in a proteosome-dependent manner during lytic replication (Chung et al., 2015, 2021). KSHV ORF59 encodes the viral processivity factor, PF-8, which interacts with and degrades PARP1, thereby enhancing the RTA-mediated transactivation, especially on the RTA promoter (Chung et al., 2015, 2021). PARP1 degradation is dependent on PF-8 interaction and recruitment of a cellular ubiquitin E3-ligase, checkpoint with FHA and RING finger domains (CHFR) (Chung et al., 2015, 2021). As the viral processivity factor is expressed as an early lytic gene following RTA expression, the PF-8-induced degradation of PARP1 may be important in reducing the inhibitory effect of PARP1 on RTA and further reinforcing the RTA positive feedback to promote lytic replication.

\section{OTHER PARPS THAT REGULATE GAMMAHERPESVIRUSES}

In addition to PARP1, other PARPs are reportedly involved in gammaherpesvirus replication. Tankyrase 1 (TNK1; PARP5) uses $\mathrm{NAD}^{+}$to PARylate the acceptors by recognizing the RxxPDG motif (TNKS-binding motif) (Smith et al., 1998; Sbodio and Chi, 2002). TNK1, TNK2 (PARP6), and telomeric repeat binding factor 2 (TRF2) interact with OriP in an EBNA1-dependent manner, as determined by the DNA affinity purification assay (Deng et al., 2002). Like PARP1, TNK1 PARylates EBNA1 and downregulates the EBNA1-dependent OriP replication (Deng et al., 2005; Tempera et al., 2010), as shown in Figure 2C. Interactome studies have identified interactions between PARPs and viral proteins. A yeast twohybrid screening for EBV viral proteins with a human cDNA library showed that EBV BRRF1, a homolog of KSHV and MHV-68 vPIP interacts with PARP4 (Calderwood et al., 2007). Furthermore, an interactome study with KSHV ORF libraries using affinity purification/LC-MS has identified PARP2 as an interaction partner of LANA (Davis et al., 2015). However, further studies should be warranted to confirm their genuine interactions and to elucidate the significance of these interactions in the context of virus life cycle.

\section{DISCUSSION}

PARP1 plays a role in various cellular mechanisms, such as DNA damage repair, cell death, proliferation, differentiation, gene transcription, and inflammation (Kim et al., 2005; Ko and Ren, 2011; Gibson and Kraus, 2012; Luo and Kraus, 2012). Additionally, it plays a role in oncogenic gammaherpesvirus infection and modulates the viral life cycle in either a positive or negative manner. Table 1 summarizes the effects of PARP1 on the life cycle of gammaherpesviruses, while Figures 2, 3 show. Although the overall effects of PARP1 on the virus life cycle either promote or inhibit the lytic replication or latency, there are a few discrepancies regarding the roles of PARP1, with reports of both positive and negative effects on the distinct stages of the life cycle of the virus. For example, several studies reported that PARP1 exerts a negative effect on the lytic replication of KSHV (Gwack et al., 2003; Wang et al., 2008; Lupey-Green et al., 2017), while a few reported its positive effect on the lytic replication of KSHV or downregulation of latent genome (Ohsaki et al., 2004; Wang et al., 2008). These discrepancies may be attributed to the differences in the experimental methods employed in individual studies. Moreover, the PARP1 inhibitor, 3-ABA is also a potent inhibitor of apoptosis, which makes it difficult to interpret the contradicting results. In addition, the virus may potentially utilize or overcome the effects of PARP1 depending on the stage of its life cycle. Furthermore, the mode of action of PARP1 can be either dependent or independent of its enzymatic activity, depending on the target proteins or DNA. Therefore, these factors should be considered when attempting to elucidate the roles 
TABLE 1 | Summary of PARP1 actions and virus interactions on regulation of gammaherpesvirus life cycle.

\begin{tabular}{|c|c|c|c|c|}
\hline $\begin{array}{l}\text { Overall } \\
\text { outcome }\end{array}$ & Life cycle & Virus & Effects of PARP1 and virus interactions & References \\
\hline \multirow[t]{3}{*}{ Positive } & Latency & EBV & $\begin{array}{l}\text { - LMP1 interacts with PARP1 and enhances the cellular PARylation levels and cellular transformation. } \\
\text { - PARP1 suppresses the EZH2 expression, reducing repressive histone modification, and induces the } \\
\text { LMP1-related protooncogene expression. } \\
\text { - The LMP1-induced PARP1 activation increases the HIF-1 } \alpha \text {-dependent gene expression. } \\
\text { - The PARylated HIF-1 } \alpha \text {-PARP1 complex binds to promoters of the HIF-1 } \alpha \text { downstream genes, } \\
\text { activating their expression and altering the cellular metabolism. }\end{array}$ & $\begin{array}{l}\text { Martin et al., 2016; } \\
\text { Hulse et al., } 2018\end{array}$ \\
\hline & \multirow[t]{2}{*}{$\begin{array}{l}\text { Lytic } \\
\text { infection }\end{array}$} & EBV & $\begin{array}{l}\text { - Treatment with a PARP1 inhibitor increases EA expression, but decreases expression of BFRF1, a } \\
\text { nuclear egress protein. } \\
\text { - Inhibition of PARP1 activity reduces the overall virion production. } \\
\text { - Inhibition of PARP1 activity increases LMP1 and EBNA2 expression. }\end{array}$ & $\begin{array}{l}\text { Mattiussi et al., } \\
2007\end{array}$ \\
\hline & & KSHV & $\begin{array}{l}\text { - PARP1 binds to KSHV ori-Lyt DNA. } \\
\text { - Increased PARP1 activity enhances the ori-Lyt DNA replication. }\end{array}$ & Wang et al., 2008 \\
\hline \multirow{3}{*}{ Negative } & \multirow[t]{3}{*}{$\begin{array}{l}\text { Lytic } \\
\text { infection }\end{array}$} & EBV & $\begin{array}{l}\text { - PARP1 binds to the BZLF1 promoter and prevents Zta from binding to the same promoter. } \\
\text { - Zta attenuates the PARylation activity of PARP1. }\end{array}$ & $\begin{array}{l}\text { Lupey-Green et al., } \\
2017\end{array}$ \\
\hline & & KSHV & $\begin{array}{l}\text { - PARP1 directly binds to and PARylates KSHV RTA, repressing the RTA-mediated transcriptional activity } \\
\text { by inhibiting the recruitment of RTA to the lytic gene promoters. } \\
\text { - KSHV vPIP directly binds to and sequesters PARP1 from RTA. } \\
\text { - KSHV Iytic replication induces PARP1 degradation. } \\
\text { - KSHV PF-8 binds to and degrades PARP1 via recruitment of a cellular ubiquitin E3 ligase, CHFR, which } \\
\text { enhances RTA transactivation. }\end{array}$ & $\begin{array}{l}\text { Gwack et al., 2003; } \\
\text { Ko et al., 2012; } \\
\text { Noh et al., 2012; } \\
\text { Chung et al., 2015, } \\
\text { 2018, } 2021\end{array}$ \\
\hline & & MHV-68 & $\begin{array}{l}\text { - PARP1 directly binds to MHV-68 RTA and inhibits its transactivation. } \\
\text { - MHV-68 RTA transactivation and lytic replication are enhanced in the PARP1 knockout cells. } \\
\text { - MHV-68 vPIP binds and sequesters PARP1 from RTA, thereby promoting RTA-mediated transactivation. } \\
\text { - MHV-68 vPIP mutant viruses with transposon insertion or triple stop codons were highly attenuated in } \\
\text { viral growth in vitro and in vivo. } \\
\text { - MHV-68 recombinant virus harboring a vPIP mutation defective in PARP1 interaction exhibits severely } \\
\text { attenuated viral growth both in vitro and in vivo. } \\
\text { - MHV-68 Iytic replication and mPF induces PARP1 degradation. }\end{array}$ & $\begin{array}{l}\text { Gwack et al., 2003; } \\
\text { Noh et al., 2012; } \\
\text { Chung et al., 2015, } \\
2018\end{array}$ \\
\hline
\end{tabular}

of PARP1 by thoroughly examining the effects of PARP1 knockdown or overexpression on virus DNA replication, lytic gene transcription, viral protein expression, and ultimately, virion production.

As PARP1 activity requires and thereby lowers the cellular $\mathrm{NAD}^{+}$levels, the activity of other $\mathrm{NAD}^{+}$-dependent deacetylases, sirtuins (SIRTs) may be affected (Houtkooper et al., 2012). PARP1 activation downregulates SIRT activity accompanied by lowered $\mathrm{NAD}^{+}$level, while SIRT1 activation reduces PARP activity, suggesting that SIRTs and PARPs compete for the cofactor $\mathrm{NAD}^{+}$(Zhang, 2003; Pillai et al., 2005; Kolthur-Seetharam et al., 2006; Bai et al., 2011). SIRT1 inhibition or knockdown reportedly induced KSHV lytic replication, increased active histone $\mathrm{H} 3 \mathrm{~K} 4 \mathrm{me} 3$ mark, and decreased histone H3K27me3 mark in the RTA promoter. SIRT1 also interacted with RTA, inhibiting its transactivation activity, thereby regulating KSHV lytic replication (Li et al., 2014). Similarly, SIRT6 reportedly bound to KSHV genome and suppressed lytic gene expression (Hu et al., 2019). It will be interesting to study how these two competing factors, SIRTs and PARPs, regulate and balance the cellular $\mathrm{NAD}^{+}$level during virus life cycle and how the gammaherpesviruses modulate these factors for their own benefit.

In conclusion, PARP1 modulates gammaherpesvirus life cycle at lytic replication or latency stage. Interestingly, gammaherpesviruses surmount the inhibitory effects of PARP1 using viral proteins that interact with PARP1 or exploit PARP1 activity for efficient replication. However, the detailed modes of action of PARP1 need to be elucidated under various conditions during virus lytic replication or latency that result in different consequences. Further investigations regarding these aspects will expand our understanding of the interactions between PARP1 and oncogenic gammaherpesviruses, which in turn may lead to identification of effective therapeutic targets for the associated diseases.

\section{AUTHOR CONTRIBUTIONS}

W-CC and MJS: conceptualization, writing_review and editing, and visualization. MJS: supervision, project administration, and 
funding acquisition. Both authors have read and agreed to the published version of the manuscript.

\section{FUNDING}

This work was supported by the National Research Foundation of Korea (NRF) grants, the Bio and Medical Technology Development Program, and the Basic Research Laboratory Program of NRF funded by the Korea government

\section{REFERENCES}

Affar, E. B., Germain, M., Winstall, E., Vodenicharov, M., Shah, R. G., Salvesen, G. S., et al. (2001). Caspase-3-mediated processing of poly (ADP-ribose) glycohydrolase during apoptosis. J. Biol. Chem. 276, 2935-2942. doi: 10.1074/ jbc.M007269200

Alemasova, E. E., and Lavrik, O. I. (2019). Poly(ADP-ribosyl)ation by PARP1: reaction mechanism and regulatory proteins. Nucleic Acids Res. 47, 3811-3827. doi: 10.1093/nar/gkz120

Altmeyer, M., Messner, S., Hassa, P. O., Fey, M., and Hottiger, M. O. (2009). Molecular mechanism of poly (ADP-ribosyl) ation by PARP1 and identification of lysine residues as ADP-ribose acceptor sites. Nucleic Acids Res. 37, 37233738. doi: 10.1093/nar/gkp229

Alvarez-Gonzalez, R., Watkins, T. A., Gill, P. K., Reed, J. L., and Mendoza-Alvarez, H. (1999). Regulatory mechanisms of poly (ADP-ribose) polymerase. Mol. Cell. Biochem. 193, 19-22.

Amé, J. C., Spenlehauer, C., and De Murcia, G. (2004). The PARP superfamily. Bioessays 26, 882-893. doi: 10.1002/bies.20085

Aneja, K. K., and Yuan, Y. (2017). Reactivation and lytic replication of kaposi's sarcoma-associated herpesvirus: an update. Front. Microbiol. 8:613. doi: 10. 3389/fmicb.2017.00613

Arvin, A., Campadelli-Fiume, G., Mocarski, E., Moore, P. S., Roizman, B., Whitley, R., et al. (2007). Human Herpesviruses: Biology, Therapy, And Immunoprophylaxis. Cambridge: Cambridge University Press.

Bai, P. (2015). Biology of Poly(ADP-Ribose) polymerases: the factotums of cell maintenance. Mol. Cell 58, 947-958. doi: 10.1016/j.molcel.2015.01.034

Bai, P., Cantó, C., Oudart, H., Brunyánszki, A., Cen, Y., Thomas, C., et al. (2011). PARP-1 inhibition increases mitochondrial metabolism through SIRT1 activation. Cell Metab. 13, 461-468. doi: 10.1016/j.cmet.2011. 03.004

Barbera, A. J., Chodaparambil, J. V., Kelley-Clarke, B., Joukov, V., Walter, J. C., Luger, K., et al. (2006a). The nucleosomal surface as a docking station for Kaposi's sarcoma herpesvirus LANA. Science 311, 856-861. doi: 10.1126/ science. 1120541

Barbera, A. J., Chodaparambil, J. V., Kelley-Clarke, B., Luger, K., and Kaye, K. M. (2006b). Kaposi's sarcoma-associated herpesvirus LANA hitches a ride on the chromosome. Cell Cycle 5, 1048-1052. doi: 10.4161/cc.5.10.2768

Beernink, P. T., Hwang, M., Ramirez, M., Murphy, M. B., Doyle, S. A., and Thelen, M. P. (2005). Specificity of protein interactions mediated by BRCT domains of the XRCC1 DNA repair protein. J. Biol. Chem. 280, 30206-30213. doi: 10.1074/jbc.M502155200

Bonfiglio, J. J., Fontana, P., Zhang, Q., Colby, T., Gibbs-Seymour, I., Atanassov, I., et al. (2017). Serine ADP-ribosylation depends on HPF1. Mol. Cell 65, 932.e-940.e. doi: 10.1016/j.molcel.2017.01.003

Bueno, M. T., Reyes, D., Valdes, L., Saheba, A., Urias, E., Mendoza, C., et al. (2013). Poly(ADP-ribose) polymerase 1 promotes transcriptional repression of integrated retroviruses. J. Virol. 87, 2496-2507. doi: 10.1128/JVI. 01668-12

Cai, Q., Verma, S. C., Lu, J., and Robertson, E. S. (2010). Molecular biology of Kaposi's sarcoma-associated herpesvirus and related oncogenesis. Adv. Virus Res. 78, 87-142. doi: 10.1016/B978-0-12-385032-4.00003-3

Calabro, M., Sheldon, J., Favero, A., Simpson, G., Fiore, J., Gomes, E., et al. (1997). Seroprevalence of Kaposi's sarcoma-associated herpesvirus/human herpesvirus 8 in several regions of Italy. J. Hum. Virol. 1, 207-213 .
(MSIT) (Nos. 2020R1A2C2013827, 2021M3A9I2080487, and 2020R1A4A1018019). W-CC was supported, in part, by a postdoctoral research grant funded by MSIT (No. NRF2019R1A6A3A01093571).

\section{ACKNOWLEDGMENTS}

We apologize the colleagues whose work has not been cited in this manuscript due to the text limit.

Caldecott, K. W., Aoufouchi, S., Johnson, P., and Shall, S. (1996). XRCC1 polypeptide interacts with DNA polymerase $\beta$ and possibly poly (ADPribose) polymerase, and DNA ligase III is a novel molecular 'nicksensor'in vitro. Nucleic Acids Res. 24, 4387-4394. doi: 10.1093/nar/24.22. 4387

Calderwood, M. A., Venkatesan, K., Xing, L., Chase, M. R., Vazquez, A., Holthaus, A. M., et al. (2007). Epstein-Barr virus and virus human protein interaction maps. Proc. Natl. Acad. Sci. U.S.A. 104, 7606-7611. doi: 10.1073/ pnas.0702332104

Chang, C. M., Yu, K. J., Mbulaiteye, S. M., Hildesheim, A., and Bhatia, K. (2009). The extent of genetic diversity of Epstein-Barr virus and its geographic and disease patterns: a need for reappraisal. Virus Res. 143, 209-221. doi: 10.1016/j. virusres.2009.07.005

Chang, H. Y., Fan, C. C., Chu, P. C., Hong, B. E., Lee, H. J., and Chang, M. S. (2011). HPuf-A/KIAA0020 modulates PARP-1 cleavage upon genotoxic stress. Cancer Res. 71, 1126-1134. doi: 10.1158/0008-5472.CAN-10-1831

Chang, Y., Cesarman, E., Pessin, M. S., Lee, F., Culpepper, J., Knowles, D. M., et al. (1994). Identification of herpesvirus-like DNA sequences in AIDSassociated Kaposi's sarcoma. Science 266, 1865-1869. doi: 10.1126/science.799 7879

Chung, W. C., Lee, S., Kim, Y., Seo, J. B., and Song, M. J. (2021). Kaposi's sarcomaassociated herpesvirus processivity factor (PF-8) recruits cellular E3 ubiquitin ligase CHFR to promote PARP1 degradation and lytic replication. PLoS Pathog. 17:e1009261. doi: 10.1371/journal.ppat.1009261

Chung, W. C., Park, J. H., Kang, H. R., and Song, M. J. (2015). Downregulation of Poly(ADP-Ribose) polymerase 1 by a viral processivity factor facilitates lytic replication of Gammaherpesvirus. J. Virol. 89, 9676-9682. doi: 10.1128/JVI. 00559- 15

Chung, W.-C., Kim, J., Kim, B. C., Kang, H.-R., Son, J., Ki, H., et al. (2018). Structure-based mechanism of action of a viral poly (ADP-ribose) polymerase 1-interacting protein facilitating virus replication. IUCrJ 5, 866-879. doi: 10 . $1107 /$ S2052252518013854

Ciccarone, F., Zampieri, M., and Caiafa, P. (2017). PARP1 orchestrates epigenetic events setting up chromatin domains. Semin. Cell Dev. Biol. 63, 123-134. doi: 10.1016/j.semcdb.2016.11.010

Corey, L., Brodie, S., Huang, M. L., Koelle, D. M., and Wald, A. (2002). HHV-8 infection: a model for reactivation and transmission. Rev. Med. Virol. 12, 47-63. doi: $10.1002 / \mathrm{rmv} .341$

Cuneo, M. J., Gabel, S. A., Krahn, J. M., Ricker, M. A., and London, R. E. (2011). The structural basis for partitioning of the XRCC1/DNA ligase III- $\alpha$ BRCTmediated dimer complexes. Nucleic Acids Res. 39, 7816-7827. doi: 10.1093/nar/ gkr419

Dandri, M., Burda, M. R., Burkle, A., Zuckerman, D. M., Will, H., Rogler, C. E., et al. (2002). Increase in de novo HBV DNA integrations in response to oxidative DNA damage or inhibition of poly(ADP-ribosyl)ation. Hepatology 35, 217-223. doi: 10.1053/jhep.2002.30203

Davidovic, L., Vodenicharov, M., Affar, E. B., and Poirier, G. G. (2001) Importance of poly (ADP-ribose) glycohydrolase in the control of poly (ADP-ribose) metabolism. Exp. Cell Res. 268, 7-13. doi: 10.1006/excr.2001. 5263

Davis, Z. H., Verschueren, E., Jang, G. M., Kleffman, K., Johnson, J. R., Park, J., et al. (2015). Global mapping of herpesvirus-host protein complexes reveals a transcription strategy for late genes. Mol. Cell 57, 349-360. doi: 10.1016/j. molcel.2014.11.026 
Demény, M. A., and Virág, L. (2021). The PARP enzyme family and the hallmarks of cancer part 1. cell intrinsic hallmarks. Cancers (Basel) 13:2042. doi: 10.3390/ cancers 13092042

Deng, Z., Atanasiu, C., Zhao, K., Marmorstein, R., Sbodio, J. I., Chi, N. W., et al. (2005). Inhibition of Epstein-Barr virus OriP function by tankyrase, a telomere-associated poly-ADP ribose polymerase that binds and modifies EBNA1. J. Virol. 79, 4640-4650. doi: 10.1128/JVI.79.8.4640-4650.2005

Deng, Z., Lezina, L., Chen, C. J., Shtivelband, S., So, W., and Lieberman, P. M. (2002). Telomeric proteins regulate episomal maintenance of Epstein-Barr virus origin of plasmid replication. Mol. Cell 9, 493-503. doi: 10.1016/s1097-2765(02) 00476-8

Di Alberti, L., Piattelli, A., Artese, L., Favia, G., Patel, S., Saunders, N., et al. (1997). Human herpesvirus 8 variants in sarcoid tissues. Lancet 350, 1655-1661. doi: 10.1016/s0140-6736(97)10102-7

Dugan, J. P., Coleman, C. B., and Haverkos, B. (2019). Opportunities to target the life cycle of epstein-barr virus (EBV) in EBV-associated lymphoproliferative disorders. Front. Oncol. 9:127. doi: 10.3389/fonc.2019.00127

Fehr, A. R., Singh, S. A., Kerr, C. M., Mukai, S., Higashi, H., and Aikawa, M. (2020). The impact of PARPs and ADP-ribosylation on inflammation and host-pathogen interactions. Genes Dev. 34, 341-359. doi: 10.1101/gad.3344 25.119

Fowler, P., Marques, S., Simas, J. P., and Efstathiou, S. (2003). ORF73 of murine herpesvirus-68 is critical for the establishment and maintenance of latency. J. Gen. Virol. 84, 3405-3416. doi: 10.1099/vir.0.19594-0

Ganem, D. (2007). KSHV-Induced Oncogenesis. Cambridge: Cambridge University Press.

Gao, S. J., Zhang, Y. J., Deng, J. H., Rabkin, C. S., Flore, O., and Jenson, H. B. (1999). Molecular polymorphism of Kaposi's sarcoma-associated herpesvirus (Human herpesvirus 8) latent nuclear antigen: evidence for a large repertoire of viral genotypes and dual infection with different viral genotypes. J. Infect. Dis. 180, 1466-1476. doi: 10.1086/315098

Gibson, B. A., and Kraus, W. L. (2012). New insights into the molecular and cellular functions of poly(ADP-ribose) and PARPs. Nat. Rev. Mol. Cell Biol. 13, 411-424. doi: $10.1038 / \mathrm{nrm} 3376$

Glover, J. N., Williams, R. S., and Lee, M. S. (2004). Interactions between BRCT repeats and phosphoproteins: tangled up in two. Trends Biochem. Sci. 29, 579-585. doi: 10.1016/j.tibs.2004.09.010

Gradoville, L., Gerlach, J., Grogan, E., Shedd, D., Nikiforow, S., Metroka, C., et al. (2000). Kaposi's sarcoma-associated herpesvirus open reading frame 50/Rta protein activates the entire viral lytic cycle in the HH-B2 primary effusion lymphoma cell line. J. Virol. 74, 6207-6212. doi: 10.1128/jvi.74.13.6207-6212. 2000

Grady, S. L., Hwang, J., Vastag, L., Rabinowitz, J. D., and Shenk, T. (2012). Herpes simplex virus 1 infection activates poly(ADP-ribose) polymerase and triggers the degradation of poly(ADP-ribose) glycohydrolase. J. Virol. 86, 8259-8268. doi: 10.1128/JVI.00495-12

Gupte, R., Liu, Z., and Kraus, W. L. (2017). PARPs and ADP-ribosylation: recent advances linking molecular functions to biological outcomes. Genes Dev. 31, 101-126. doi: 10.1101/gad.291518.116

Gwack, Y., Nakamura, H., Lee, S. H., Souvlis, J., Yustein, J. T., Gygi, S., et al. (2003). Poly(ADP-ribose) polymerase 1 and Ste20-like kinase hKFC act as transcriptional repressors for gamma-2 herpesvirus lytic replication. Mol. Cell Biol. 23, 8282-8294. doi: 10.1128/MCB.23.22.8282-8294.2003

Ha, H. C., Juluri, K., Zhou, Y., Leung, S., Hermankova, M., and Snyder, S. H. (2001). Poly(ADP-ribose) polymerase-1 is required for efficient HIV-1 integration. Proc. Natl. Acad. Sci. U.S.A. 98, 3364-3368. doi: 10.1073/pnas.05163 3498

Habison, A. C., Beauchemin, C., Simas, J. P., Usherwood, E. J., and Kaye, K. M. (2012). Murine Gammaherpesvirus 68 LANA acts on terminal repeat DNA to mediate episome persistence. J. Virol. 86, 11863-11876. doi: 10.1128/JVI.01 656-12

Hassa, P. O., and Hottiger, M. O. (2008). The diverse biological roles of mammalian PARPS, a small but powerful family of poly-ADP-ribose polymerases. Front. Biosci. 13, 3046-3082. doi: 10.2741/2909

Henke-Gendo, C., and Schulz, T. F. (2004). Transmission and disease association of Kaposi's sarcoma-associated herpesvirus: recent developments. Curr. Opin. Infect. Dis. 17, 53-57. doi: 10.1097/00001432-200402000-00011
Hottiger, M. O., Hassa, P. O., Lüscher, B., Schüler, H., and Koch-Nolte, F. (2010). Toward a unified nomenclature for mammalian ADP-ribosyltransferases. Trends Biochem. Sci. 35, 208-219. doi: 10.1016/j.tibs.2009.12.003

Houtkooper, R. H., Pirinen, E., and Auwerx, J. (2012). Sirtuins as regulators of metabolism and healthspan. Nat. Rev. Mol. Cell Biol. 13, 225-238. doi: 10.1038/ nrm3293

Hu, J., Garber, A. C., and Renne, R. (2002). The latency-associated nuclear antigen of Kaposi's sarcoma-associated herpesvirus supports latent DNA replication in dividing cells. J. Virol. 76, 11677-11687. doi: 10.1128/jvi.76.22.11677-11687. 2002

Hu, M., Armstrong, N., Seto, E., Li, W., Zhu, F., Wang, P. C., et al. (2019). Sirtuin 6 Attenuates Kaposi's Sarcoma-Associated herpesvirus reactivation by suppressing ori-lyt activity and expression of RTA. J. Virol. 93, e02200-e2218. doi: 10.1128/JVI.02200-18

Hulse, M., Caruso, L. B., Madzo, J., Tan, Y., Johnson, S., and Tempera, I. (2018). Poly(ADP-ribose) polymerase 1 is necessary for coactivating hypoxia-inducible factor-1-dependent gene expression by Epstein-Barr virus latent membrane protein 1. PLoS Pathog 14:e1007394. doi: 10.1371/journal.ppat.1007394

Jha, H. C., Banerjee, S., and Robertson, E. S. (2016). The role of Gammaherpesviruses in cancer pathogenesis. Pathogens 5:18. doi: $10.3390 /$ pathogens5010018

Jubin, T., Kadam, A., Jariwala, M., Bhatt, S., Sutariya, S., Gani, A., et al. (2016). The PARP family: insights into functional aspects of poly (ADP-ribose) polymerase1 in cell growth and survival. Cell Prolif. 49, 421-437. doi: 10.1111/cpr. 12268

Kamaletdinova, T., Fanaei-Kahrani, Z., and Wang, Z. Q. (2019). The enigmatic function of PARP1: from PARylation activity to PAR readers. Cells 8:1625. doi: $10.3390 /$ cells 8121625

Kameoka, M., Nukuzuma, S., Itaya, A., Tanaka, Y., Ota, K., Inada, Y., et al. (2005). Poly(ADP-ribose)polymerase-1 is required for integration of the human immunodeficiency virus type 1 genome near centromeric alphoid DNA in human and murine cells. Biochem. Biophys. Res. Commun. 334, 412-417. doi: 10.1016/j.bbrc.2005.06.104

Kameoka, M., Tanaka, Y., Ota, K., Itaya, A., and Yoshihara, K. (1999). Poly (ADPribose) polymerase is involved in PMA-induced activation of HIV-1 in U1 cells by modulating the LTR function. Biochem. Biophys. Res. Commun. 262, 285-289. doi: 10.1006/bbrc.1999.1146

Kanno, S., Kuzuoka, H., Sasao, S., Hong, Z., Lan, L., Nakajima, S., et al. (2007). A novel human AP endonuclease with conserved zinc-finger-like motifs involved in DNA strand break responses. EMBO J. 26, 2094-2103. doi: 10.1038/sj.emboj. 7601663

Kawaichi, M., Ueda, K., and Hayaishi, O. (1980). Initiation of poly(ADP-ribosyl) histone synthesis by poly(ADP-ribose) synthetase. J. Biol. Chem. 255, 816-819. doi: 10.1016/s0021-9258(19)86100-8

Ke, Y., Wang, C., Zhang, J., Zhong, X., Wang, R., Zeng, X., et al. (2019). The Role of PARPs in inflammation-and metabolic-related diseases: molecular mechanisms and beyond. Cells 8:1047. doi: 10.3390/cells8091047

Kennedy, G., and Sugden, B. (2003). EBNA-1, a bifunctional transcriptional activator. Mole. Cell. Biol. 23, 6901-6908. doi: 10.1128/MCB.23.19.6901-6908. 2003

Kiehl, A., and Dorsky, D. I. (1991). Cooperation of EBV DNA polymerase and EA$\mathrm{D}$ (BMRF1) in vitro and colocalization in nuclei of infected cells. Virology 184, 330-340. doi: 10.1016/0042-6822(91)90849-7

Kim, M. Y., Zhang, T., and Kraus, W. L. (2005). Poly(ADP-ribosyl)ation by PARP1: 'PAR-laying' NAD+ into a nuclear signal. Genes Dev. 19, 1951-1967. doi: 10.1101/gad.1331805

Ko, H. L., and Ren, E. C. (2011). Novel poly (ADP-ribose) polymerase 1 binding motif in hepatitis B virus core promoter impairs DNA damage repair. Hepatology 54, 1190-1198. doi: 10.1002/hep.24502

Ko, H. L., and Ren, E. C. (2012). Functional aspects of PARP1 in DNA repair and transcription. Biomolecules 2, 524-548. doi: 10.3390/biom204 0524

Ko, Y.-C., Tsai, W.-H., Wang, P.-W., Wu, I.-L., Lin, S.-Y., Chen, Y.-L., et al. (2012). Suppressive regulation of KSHV RTA with O-GlcNAcylation. J. Biomed. Sci. 19:12. doi: 10.1186/1423-0127-19-12

Kolthur-Seetharam, U., Dantzer, F., Mcburney, M. W., De Murcia, G., and SassoneCorsi, P. (2006). Control of AIF-mediated cell death by the functional interplay 
of SIRT1 and PARP-1 in response to DNA damage. Cell Cycle 5, 873-877. doi: 10.4161/cc.5.8.2690

Kotoglou, P., Kalaitzakis, A., Vezyraki, P., Tzavaras, T., Michalis, L. K., Dantzer, F., et al. (2009). Hsp70 translocates to the nuclei and nucleoli, binds to XRCC1 and PARP-1, and protects HeLa cells from single-strand DNA breaks. Cell Stress Chaperones 14, 391-406. doi: 10.1007/s12192-008-0093-6

Kraus, W. L., and Lis, J. T. (2003). PARP goes transcription. Cell 113, 677-683.

Krishnakumar, R., and Kraus, W. L. (2010). The PARP side of the nucleus: molecular actions, physiological outcomes, and clinical targets. Mol. Cell 39, 8-24. doi: 10.1016/j.molcel.2010.06.017

Langelier, M. F., Planck, J. L., Roy, S., and Pascal, J. M. (2012). Structural basis for DNA damage-dependent poly(ADP-ribosyl)ation by human PARP-1. Science 336, 728-732. doi: 10.1126/science.1216338

Langelier, M. F., Servent, K. M., Rogers, E. E., and Pascal, J. M. (2008). A third zinc-binding domain of human poly(ADP-ribose) polymerase- 1 coordinates DNA-dependent enzyme activation. J. Biol. Chem. 283, 4105-4114. doi: 10. 1074/jbc.m708558200

Langelier, M.-F., Planck, J. L., Roy, S., and Pascal, J. M. (2011). Crystal structures of poly (ADP-ribose) polymerase-1 (PARP-1) zinc fingers bound to DNA: structural and functional insights into DNA-dependent PARP-1 activity. J. Biol. Chem. 286, 10690-10701. doi: 10.1074/jbc.M110.202507

Lee, H.-R., Brulois, K., Wong, L., and Jung, J. U. (2012). Modulation of immune system by Kaposi's sarcoma-associated herpesvirus: lessons from viral evasion strategies. Front. Microbiol. 3:44. doi: 10.3389/fmicb.2012. 00044

Li, H. P., and Chang, Y. S. (2003). Epstein-Barr virus latent membrane protein 1: structure and functions. J. Biomed. Sci. 10, 490-504. doi: 10.1007/BF0225 6110

Li, Q., He, M., Zhou, F., Ye, F., and Gao, S.-J. (2014). Activation of Kaposi's sarcoma-associated herpesvirus by inhibitors of class III histone deacetylases: identification of SIRT1 as a regulator of KSHV life cycle. J. Virol. 88, 6355-6367. doi: 10.1128/JVI.00219-14

Li, Y., Oh, H. J., and Lau, Y. F. (2006). The poly(ADP-ribose) polymerase 1 interacts with Sry and modulates its biological functions. Mol. Cell Endocrinol. 25, 35-46. doi: $10.1016 /$ j.mce.2006.06.008

Lindner, S. E., and Sugden, B. (2007). The plasmid replicon of Epstein-Barr virus: mechanistic insights into efficient, licensed, extrachromosomal replication in human cells. Plasmid 58, 1-12. doi: 10.1016/j.plasmid.2007.01.003

Liu, L., Lear, Z., Hughes, D. J., Wu, W., Zhou, E. M., Whitehouse, A., et al. (2015). Resolution of the cellular proteome of the nucleocapsid protein from a highly pathogenic isolate of porcine reproductive and respiratory syndrome virus identifies PARP- 1 as a cellular target whose interaction is critical for virus biology. Vet. Microbiol. 176, 109-119. doi: 10.1016/j.vetmic.2014.11.023

Liu, S., Pavlova, I. V., Virgin, H. W. T., and Speck, S. H. (2000). Characterization of Gammaherpesvirus 68 gene 50 transcription. J. Virol. 74, 2029-2037. doi: 10.1128/jvi.74.4.2029-2037.2000

Liu, X., Li, Y., Peng, S., Yu, X., Li, W., Shi, F., et al. (2018). Epstein-Barr virus encoded latent membrane protein 1 suppresses necroptosis through targeting RIPK1/3 ubiquitination. Cell Death Dis. 9:53. doi: 10.1038/s41419-017-0081-9

Lukac, D. M., and Yuan, Y. (2007). "Reactivation and lytic replication of KSHV," in Human Herpesviruses: Biology, Therapy, and Immunoprophylaxis, eds A. Arvin, G. Campadelli-Fiume, E. Mocarski, P. S. Moore, B. Roizman, R. Whitley, et al. (Cambridge: Cambridge University Press).

Lukac, D. M., Kirshner, J. R., and Ganem, D. (1999). Transcriptional activation by the product of open reading frame 50 of Kaposi's sarcoma-associated herpesvirus is required for lytic viral reactivation in B cells. J. Virol. 73, 9348-9361. doi: 10.1128/JVI.73.11.9348-9361.1999

Lukac, D. M., Renne, R., Kirshner, J. R., and Ganem, D. (1998). Reactivation of Kaposi's sarcoma-associated herpesvirus infection from latency by expression of the ORF 50 transactivator, a homolog of the EBV R protein. Virology 252, 304-312. doi: 10.1006/viro.1998.9486

Luo, X., and Kraus, W. L. (2012). On PAR with PARP: cellular stress signaling through poly(ADP-ribose) and PARP-1. Genes Dev. 26, 417-432. doi: 10.1101/ gad.183509.111

Lupey-Green, L. N., Caruso, L. B., Madzo, J., Martin, K. A., Tan, Y., Hulse, M., et al. (2018). PARP1 stabilizes CTCF binding and chromatin structure to maintain Epstein-Barr virus latency type. J. Virol. 92, e755-e818. doi: 10.1128/JVI.00 $755-18$
Lupey-Green, L. N., Moquin, S. A., Martin, K. A., Mcdevitt, S. M., Hulse, M., Caruso, L. B., et al. (2017). PARP1 restricts Epstein Barr virus lytic reactivation by binding the BZLF1 promoter. Virology 507, 220-230. doi: 10.1016/j.virol. 2017.04 .006

Luzuriaga, K., and Sullivan, J. L. (2010). Infectious mononucleosis. N. Engl. J. Med. 362, 1993-2000. doi: 10.1056/NEJMcp1001116

Mangerich, A., and Bürkle, A. (2012). Pleiotropic cellular functions of PARP1 in longevity and aging: genome maintenance meets inflammation. Oxid. Med. Cell Longev. 2012:321653. doi: 10.1155/2012/321653

Martin, K. A., Lupey, L. N., and Tempera, I. (2016). Epstein-Barr Virus Oncoprotein LMP1 mediates epigenetic changes in host gene expression through PARP1. J. Virol. 90, 8520-8530. doi: 10.1128/JVI.01180-16

Martro, E., Bulterys, M., Stewart, J., Spira, T., Cannon, M., Thacher, T., et al. (2004). Comparison of human herpesvirus 8 and Epstein-Barr virus seropositivity among children in areas endemic and non-endemic for Kaposi's sarcoma. J. Med. Virol. 72, 126-131. doi: 10.1002/jmv.10548

Masson, M., Niedergang, C., Schreiber, V., Muller, S., Menissier-De Murcia, J., and De Murcia, G. (1998). XRCC1 is specifically associated with poly (ADP-ribose) polymerase and negatively regulates its activity following DNA damage. $\mathrm{Mol}$. Cell Biol. 18, 3563-3571. doi: 10.1128/MCB.18.6.3563

Mattiussi, S., Tempera, I., Matusali, G., Mearini, G., Lenti, L., Fratarcangeli, S., et al. (2007). Inhibition of Poly(ADP-ribose)polymerase impairs Epstein Barr Virus lytic cycle progression. Infect. Agent Cancer 2:18. doi: 10.1186/1750-93 78-2-18

Mayama, S., Cuevas, L. E., Sheldon, J., Omar, O. H., Smith, D. H., Okong, P., et al. (1998). Prevalence and transmission of Kaposi's sarcoma-associated herpesvirus (human herpesvirus 8) in Ugandan children and adolescents. Int. J. Cancer 77, 817-820. doi: 10.1002/(sici)1097-0215(19980911)77:6\&lt;817::aid-ijc2\&gt; 3.0.co; $2-\mathrm{x}$

McGeoch, D. J., and Davison, A. J. (1999). The descent of human herpesvirus 8. Semin. Cancer Biol. 9, 201-209. doi: 10.1006/scbi.1999.0093

Mendoza-Alvarez, H., and Alvarez-Gonzalez, R. (1993). Poly (ADP-ribose) polymerase is a catalytic dimer and the automodification reaction is intermolecular. J. Biol. Chem. 268, 22575-22580. doi: 10.1016/s0021-9258(18) 41568-2

Moorman, N. J., Willer, D. O., and Speck, S. H. (2003). The gammaherpesvirus 68 latency-associated nuclear antigen homolog is critical for the establishment of splenic latency. J. Virol. 77, 10295-10303. doi: 10.1128/jvi.77.19.10295-10303. 2003

Murata, T. (2014). Regulation of Epstein-Barr virus reactivation from latency. Microbiol. Immunol. 58, 307-317. doi: 10.1111/1348-0421.12155

Myoung, J., and Ganem, D. (2011). Infection of primary human tonsillar lymphoid cells by KSHV reveals frequent but abortive infection of T cells. Virology 413, 1-11. doi: 10.1016/j.virol.2010.12.036

Na, T. Y., Ka, N. L., Rhee, H., Kyeong, D., Kim, M. H., Seong, J. K., et al. (2016). Interaction of hepatitis $\mathrm{B}$ virus $\mathrm{X}$ protein with PARP1 results in inhibition of DNA repair in hepatocellular carcinoma. Oncogene 35, 5435-5445. doi: 10. 1038/onc.2016.82

Nargi-Aizenman, J. L., Simbulan-Rosenthal, C. M., Kelly, T. A., Smulson, M. E., and Griffin, D. E. (2002). Rapid activation of poly(ADP-ribose) polymerase contributes to Sindbis virus and staurosporine-induced apoptotic cell death. Virology 293, 164-171. doi: 10.1006/viro.2001.1253

Nash, A. A., Dutia, B. M., Stewart, J. P., and Davison, A. J. (2001). Natural history of murine gamma-herpesvirus infection. Philos. Trans. R. Soc. Lond. B Biol. Sci. 356, 569-579. doi: 10.1098/rstb.2000.0779

Neuhierl, B., and Delecluse, H. J. (2006). The Epstein-Barr virus BMRF1 gene is essential for lytic virus replication. J. Virol. 80, 5078-5081. doi: 10.1128/JVI.80. 10.5078-5081.2006

Niller, H. H., Szenthe, K., and Minarovits, J. (2014). Epstein-Barr virus-host cell interactions: an epigenetic dialog? Front. Genet. 5:367. doi: 10.3389/fgene.2014. 00367

Noh, C.-W., Cho, H.-J., Kang, H.-R., Jin, H. Y., Lee, S., Deng, H., et al. (2012). The virion-associated open reading frame 49 of murine gammaherpesvirus 68 promotes viral replication both in vitro and in vivo as a derepressor of RTA. J. Virol. 86, 1109-1118. doi: 10.1128/JVI.05785-11

Ogata, N., Ueda, K., and Hayaishi, O. (1980a). ADP-ribosylation of histone H2B. Identification of glutamic acid residue 2 as the modification site. J. Biol. Chem. $255,7610-7615$. 
Ogata, N., Ueda, K., Kagamiyama, H., and Hayaishi, O. (1980b). ADP-ribosylation of histone H1. Identification of glutamic acid residues 2, 14, and the COOHterminal lysine residue as modification sites. J. Biol. Chem. 255, 7616-7620.

Ohsaki, E., Ueda, K., Sakakibara, S., Do, E., Yada, K., and Yamanishi, K. (2004). Poly(ADP-ribose) polymerase 1 binds to Kaposi's sarcoma-associated herpesvirus (KSHV) terminal repeat sequence and modulates KSHV replication in latency. J. Virol. 78, 9936-9946. doi: 10.1128/JVI.78.18.9936-9946.2004

Oka, J., Ueda, K., Hayaishi, O., Komura, H., and Nakanishi, K. (1984). ADP-ribosyl protein lyase. Purification, properties, and identification of the product. J. Biol. Chem. 259, 986-995.

Oka, S., Kato, J., and Moss, J. (2006). Identification and characterization of a mammalian 39-kDa poly(ADP-ribose) glycohydrolase. J. Biol. Chem. 281, 705-713. doi: 10.1074/jbc.M510290200

Parent, M., Yung, T. M., Rancourt, A., Ho, E. L., Vispé, S., Suzuki-Matsuda, F., et al. (2005). Poly (ADP-ribose) polymerase-1 is a negative regulator of HIV1 transcription through competitive binding to TAR RNA with tat positive transcription elongation factor b (p-TEFb) complex. J. Biol. Chem. 280, 448457. doi: 10.1074/jbc.M408435200

Park, E., and Griffin, D. E. (2009). Interaction of Sindbis virus non-structural protein 3 with poly(ADP-ribose) polymerase 1 in neuronal cells. J. Gen. Virol. 90, 2073-2080. doi: 10.1099/vir.0.012682-0

Pillai, J. B., Isbatan, A., Imai, S., and Gupta, M. P. (2005). Poly(ADP-ribose) polymerase-1-dependent cardiac myocyte cell death during heart failure is mediated by NAD+ depletion and reduced Sir2alpha deacetylase activity. J. Biol. Chem. 280, 43121-43130. doi: 10.1074/jbc.M506162200

Price, A. M., and Luftig, M. A. (2015). To be or not IIb: a multi-step process for Epstein-Barr virus latency establishment and consequences for B cell tumorigenesis. PLoS Pathog. 11:e1004656. doi: 10.1371/journal.ppat.1004656

Purushothaman, P., Dabral, P., Gupta, N., Sarkar, R., and Verma, S. C. (2016) KSHV genome replication and maintenance. Front. Microbiol. 7:54. doi: 10. 3389/fmicb.2016.00054

Rainbow, L., Platt, G. M., Simpson, G. R., Sarid, R., Gao, S. J., Stoiber, H., et al. (1997). The 222- to 234-kilodalton latent nuclear protein (LNA) of Kaposi's sarcoma-associated herpesvirus (human herpesvirus 8) is encoded by orf73 and is a component of the latency-associated nuclear antigen. J. Virol. 71, 5915-5921. doi: 10.1128/JVI.71.8.5915-5921.1997

Ray Chaudhuri, A., and Nussenzweig, A. (2017). The multifaceted roles of PARP1 in DNA repair and chromatin remodelling. Nat. Rev. Mol. Cell Biol. 18, 610-621. doi: $10.1038 / \mathrm{nrm} .2017 .53$

Rettig, M. B., Ma, H. J., Vescio, R. A., Pold, M., Schiller, G., Belson, D., et al. (1997). Kaposi's sarcoma-associated herpesvirus infection of bone marrow dendritic cells from multiple myeloma patients. Science 276, 1851-1854. doi: 10.1126/ science.276.5320.1851

Rickinson, A. (2002). Epstein-Barr virus. Virus Res. 82, 109-113. doi: 10.1016/ s0168-1702(01)00436-1

Rickinson, A. B. (2014). Co-infections, inflammation and oncogenesis: future directions for EBV research. Semin. Cancer Biol. 26, 99-115. doi: 10.1016/j. semcancer.2014.04.004

Rochford, R., Lutzke, M. L., Alfinito, R. S., Clavo, A., and Cardin, R. D. (2001). Kinetics of murine gammaherpesvirus 68 gene expression following infection of murine cells in culture and in mice. J. Virol. 75, 4955-4963. doi: 10.1128/JVI. 75.11.4955-4963.2001

Rodríguez, M. I., González-Flores, A., Dantzer, F., Collard, J., De Herreros, A. G., and Oliver, F. J. (2011). Poly(ADP-ribose)-dependent regulation of Snail1 protein stability. Oncogene 30, 4365-4372. doi: 10.1038/onc.2011.153

Roizman, B., Carmichael, L., Deinhardt, F., Nahmias, A., Plowright, W., Rapp, F., et al. (1981). Herpesviridae. Intervirology 16, 201-217. doi: 10.1159/000149269

Rom, S., Reichenbach, N. L., Dykstra, H., and Persidsky, Y. (2015). The dual action of poly(ADP-ribose) polymerase -1 (PARP-1) inhibition in HIV-1 infection: HIV-1 LTR inhibition and diminution in Rho GTPase activity. Front. Microbiol. 6:878. doi: 10.3389/fmicb.2015.00878

Rosenthal, F., Feijs, K. L., Frugier, E., Bonalli, M., Forst, A. H., Imhof, R., et al. (2013). Macrodomain-containing proteins are new mono-ADPribosylhydrolases. Nat. Struct. Mol. Biol. 20, 502-507. doi: 10.1038/nsmb.2521

Sbodio, J. I., and Chi, N. W. (2002). Identification of a tankyrase-binding motif shared by IRAP. TAB182, and human TRF1 but not mouse TRF1. NuMA contains this RXXPDG motif and is a novel tankyrase partner. J. Biol. Chem. 277, 31887-31892. doi: 10.1074/jbc.M203916200
Schulz, T. F., and Chang, Y. (2007). "KSHV gene expression and regulation," in Human Herpesviruses: Biology, Therapy, and Immunoprophylaxis, eds A. Arvin, G. Campadelli-Fiume, E. Mocarski, P. S. Moore, B. Roizman, R. Whitley, et al. (Cambridge: Cambridge University Press).

Shair, K. H., Bendt, K. M., Edwards, R. H., Nielsen, J. N., Moore, D. T., and Raab-Traub, N. (2012). Epstein-Barr virus-encoded latent membrane protein 1 (LMP1) and LMP2A function cooperatively to promote carcinoma development in a mouse carcinogenesis model. J. Virol. 86, 5352-5365. doi: 10.1128/JVI.07035-11

Sharifi, R., Morra, R., Appel, C. D., Tallis, M., Chioza, B., Jankevicius, G., et al. (2013). Deficiency of terminal ADP-ribose protein glycohydrolase TARG1/C6orf130 in neurodegenerative disease. EMBO J. 32, 1225-1237. doi: 10.1038/emboj.2013.51

Shou, Q., Fu, H., Huang, X., and Yang, Y. (2019). PARP-1 controls NK cell recruitment to the site of viral infection. JCI Insight 4:e121291 doi: 10.1172/jci. insight.121291

Simas, J. P., and Efstathiou, S. (1998). Murine gammaherpesvirus 68: a model for the study of gammaherpesvirus pathogenesis. Trends Microbiol. 6, 276-282. doi: 10.1016/s0966-842x(98)01306-7

Simpson, G. R., Schulz, T. F., Whitby, D., Cook, P. M., Boshoff, C., Rainbow, L., et al. (1996). Prevalence of Kaposi's sarcoma associated herpesvirus infection measured by antibodies to recombinant capsid protein and latent immunofluorescence antigen. Lancet 348, 1133-1138. doi: 10.1016/S01406736(96)07560-5

Smith, S., Giriat, I., Schmitt, A., and De Lange, T. (1998). Tankyrase, a poly(ADPribose) polymerase at human telomeres. Science 282, 1484-1487. doi: 10.1126/ science.282.5393.1484

Speck, S. H., and Virgin, H. W. (1999). Host and viral genetics of chronic infection: a mouse model of gamma-herpesvirus pathogenesis. Curr. Opin. Microbiol. 2, 403-409. doi: 10.1016/s1369-5274(99)80071-x

Srinivas, S. K., Sample, J. T., and Sixbey, J. W. (1998). Spontaneous loss of viral episomes accompanying Epstein-Barr virus reactivation in a Burkitt's lymphoma cell line. J. Infect. Dis. 177, 1705-1709. doi: 10.1086/51 7427

Strosznajder, R. P., Jesko, H., and Zambrzycka, A. (2005). Poly(ADP-ribose) polymerase: the nuclear target in signal transduction and its role in brain ischemia-reperfusion injury. Mol. Neurobiol. 31, 149-167. doi: 10.1385/MN:31: 1-3:149

Sun, R., Lin, S. F., Gradoville, L., Yuan, Y., Zhu, F., and Miller, G. (1998). A viral gene that activates lytic cycle expression of Kaposi's sarcoma-associated herpesvirus. Proc. Natl. Acad. Sci. U.S.A. 95, 10866-10871. doi: 10.1073/pnas. 95.18.10866

Tao, Z., Gao, P., and Liu, H.-W. (2009). Identification of the ADP-ribosylation sites in the PARP-1 automodification domain: analysis and implications. J. Am. Chem. Soc. 131, 14258-14260. doi: 10.1021/ja906135d

Tempera, I., Deng, Z., Atanasiu, C., Chen, C. J., D'erme, M., and Lieberman, P. M. (2010). Regulation of Epstein-Barr virus OriP replication by poly(ADP-ribose) polymerase 1. J. Virol. 84, 4988-4997. doi: 10.1128/JVI. 02333-09

Tsurumi, T. (1993). Purification and characterization of the DNA-binding activity of the Epstein-Barr virus DNA polymerase accessory protein BMRF1 gene products, as expressed in insect cells by using the baculovirus system. J. Virol. 67, 1681-1687. doi: 10.1128/JVI.67.3.1681-1687.1993

Ubol, S., Park, S., Budihardjo, I., Desnoyers, S., Montrose, M. H., Poirier, G. G., et al. (1996). Temporal changes in chromatin, intracellular calcium, and poly(ADPribose) polymerase during Sindbis virus-induced apoptosis of neuroblastoma cells. J. Virol. 70, 2215-2220. doi: 10.1128/JVI.70.4.2215-2220.1996

Virgin, H. W., and Speck, S. H. (1999). Unraveling immunity to gammaherpesviruses: a new model for understanding the role of immunity in chronic virus infection. Curr. Opin. Immunol. 11, 371-379. doi: 10.1016/s0952-7915(99) 80063-6

Wang, Y., Li, H., Tang, Q., Maul, G. G., and Yuan, Y. (2008). Kaposi's sarcoma-associated herpesvirus ori-Lyt-dependent DNA replication: involvement of host cellular factors. J. Virol. 82, 2867-2882. doi: 10.1128/JVI. 01319-07

Wei, F., Gan, J., Wang, C., Zhu, C., and Cai, Q. (2016). Cell cycle regulatory functions of the KSHV oncoprotein LANA. Front. Microbiol. 7:334. doi: 10. 3389/fmicb.2016.00334 
Whitby, D., and Boshoff, C. (1998). Kaposi's sarcoma herpesvirus as a new paradigm for virus-induced oncogenesis. Curr. Opin. Oncol. 10, 405-412. doi: 10.1097/00001622-199809000-00007

Wu, T. T., Usherwood, E. J., Stewart, J. P., Nash, A. A., and Sun, R. (2000). Rta of murine gammaherpesvirus 68 reactivates the complete lytic cycle from latency. J. Virol. 74, 3659-3667. doi: 10.1128/jvi.74.8.3659-3667.2000

Xia, C., Wolf, J. J., Sun, C., Xu, M., Studstill, C. J., Chen, J., et al. (2020). PARP1 enhances influenza a virus propagation by facilitating degradation of host type i interferon receptor. J. Virol. 94, e01572-e01619. doi: 10.1128/JVI. 01572-19

Xie, S., Mortusewicz, O., Ma, H. T., Herr, P., Poon, R. Y., Helleday, T., et al. (2015). Timeless interacts with PARP-1 to promote homologous recombination repair. Mol. Cell 60, 163-176. doi: 10.1016/j.molcel.2015.07.031

Xu, Y., Aucoin, D. P., Huete, A. R., Cei, S. A., Hanson, L. J., and Pari, G. S. (2005). A Kaposi's sarcoma-associated herpesvirus/human herpesvirus 8 ORF50 deletion mutant is defective for reactivation of latent virus and DNA replication. J. Virol. 79, 3479-3487. doi: 10.1128/JVI.79.6.3479-3487.2005

Yan, L., Majerciak, V., Zheng, Z. M., and Lan, K. (2019). Towards better understanding of KSHV life cycle: from transcription and posttranscriptional regulations to pathogenesis. Virol. Sin. 34, 135-161. doi: 10.1007/s12250-01900114-3

Ye, F., Lei, X., and Gao, S.-J. (2011). Mechanisms of Kaposi's sarcoma-associated herpesvirus latency and reactivation. Adv. Virol. 2011:193860. doi: 10.1155/ 2011/193860

Young, L. S., Arrand, J. R., and Murray, P. G. (2007). "EBV gene expression and regulation," in Human Herpesviruses: Biology, therapy, and immunoprophylaxis, eds A. Arvin, G. Campadelli-Fiume, E. Mocarski, P. S. Moore, B. Roizman, R. Whitley, et al. (Cambridge: Cambridge University Press).

Zhang, J. (2003). Are poly(ADP-ribosyl)ation by PARP-1 and deacetylation by Sir2 linked? Bioessays 25, 808-814. doi: 10.1002/bies.10317

Zhang, Z., Hildebrandt, E. F., Simbulan-Rosenthal, C. M., and Anderson, M. G. (2002). Sequence-specific binding of poly(ADP-ribose) polymerase-1 to the human T cell leukemia virus type-I tax responsive element. Virology 296, 107-116. doi: 10.1006/viro.2002.1385

Conflict of Interest: The authors declare that the research was conducted in the absence of any commercial or financial relationships that could be construed as a potential conflict of interest.

Publisher's Note: All claims expressed in this article are solely those of the authors and do not necessarily represent those of their affiliated organizations, or those of the publisher, the editors and the reviewers. Any product that may be evaluated in this article, or claim that may be made by its manufacturer, is not guaranteed or endorsed by the publisher.

Copyright (C) 2022 Chung and Song. This is an open-access article distributed under the terms of the Creative Commons Attribution License (CC BY). The use, distribution or reproduction in other forums is permitted, provided the original author(s) and the copyright owner(s) are credited and that the original publication in this journal is cited, in accordance with accepted academic practice. No use, distribution or reproduction is permitted which does not comply with these terms. 